\title{
Organization of rational use of agricultural land on a landscape-ecological basis
}

\author{
Marina Podkovyrova ${ }^{1, *}$, Olga Volobueva $^{1}$, Dmitriy Kucherov ${ }^{1}$, and Larisa Gilyova ${ }^{1}$ \\ ${ }^{1}$ Industrial University of Tyumen, Volodarsky Street, 38, 625000, Tyumen, Russia
}

\begin{abstract}
The aim of the study is to develop a project for the rational organization of the use of agricultural land for land use on the basis of a comprehensive integrated assessment and landscape-ecological analysis, involving their landscape-ecological optimization, conservation of landscape diversity. This project will establish the main criteria for the optimization of agricultural lands as natural-economic systems: land and resource security; level of forest cover; agricultural load on landscapes (erosion level, specific gravity of irrigated and drained lands, livestock load per 100 ha of fodder land); the degree of agrogenic load on agrolandscapes (specific gravity of steam, indicators of plowing and agricultural development); landscape-ecological conditions (landscape situation, drainage of landscapes, relief, soil; water and radiation balances; manifestation of adverse physical and geographical processes); spatial and technological conditions (a variety of landscape patterns of arable land and other lands, their configuration and size); the degree of environmental tension (the degree of development of natural physical and geographical processes and anthropogenic ones: salinization, waterlogging, flooding, pollution of soils, snow, air and water basins, etc.); the amount of agricultural losses; environmental, social and economic efficiency of the implementation of design developments. The methods used are: abstractlogical, integrated landscape and environmental assessment, cartographic, modeling methods.
\end{abstract}

\section{Introduction}

The landscape-ecological approach to solving the issues of rational organization of agricultural land use ensures the creation of sustainable land uses by taking into account the classes of soil suitability (biological characteristics of soils, the involvement of forest soils in agricultural circulation (with the consolidation of land shares) [1-10]. Based on the goal, the following project tasks were solved:

1. The features of formation and development of specific agricultural land use were investigated.

2. The criteria for optimizing natural-economic systems were established $[1,3]$.

3. Soil suitability classes were defined.

4. A landscape-ecological analysis of the state of agricultural land was performed $[1,4,9]$.

* Corresponding author: podkovyrova.54@mail.ru 
5. The landscape-ecological mapping of the territory was carried out.

6. The degree of the ecological and economic condition of agricultural lands was established.

7. A set of measures for the rational use of agricultural lands (landscape-ecological optimization of natural-economic systems) has been developed.

When developing the project, the authors used the following methods: abstract-logical method, modeling method, calculation-variant method, thematic mapping.

\section{Results and discussion}

The basis for identifying soil suitability classes was the possibility of appropriate use of land for the main types of agricultural land. On the territory of the studied land use, the soils are represented by three classes of soil suitability (Table 1) [6]:

1. The second soil suitability class is characteristic of lands suitable for arable land with restrictions on use, which require measures aimed at increasing fertility, improving waterphysical and other soil properties (black-earth soil, gray forest, meadow, black-earth meadow soils, and salt licks).

2. The third soil suitability class is represented by lands suitable for forage lands that do not require restrictions in their use (black-earth and meadow soils).

3. The fourth soil suitability class includes lands that are limitedly suitable for forage lands (salt licks and meadow-boggy soils).

Table 1. Characteristics of the agricultural land suitability classes.

\begin{tabular}{|c|c|c|c|c|c|}
\hline \multirow{2}{*}{ Land } & \multicolumn{5}{|c|}{ Agricultural land suitability classes, area (ha) } \\
\cline { 2 - 6 } & 1 & 2 & 3 & 4 & 5 \\
\hline Arable land & - & 2,600 & 1,000 & 298.7 & - \\
\hline Hayfield & - & - & 1,964 & $2,752.73$ & - \\
\hline Pastureland & - & - & 2,650 & $2,452.42$ & - \\
\hline Total agricultural land & - & 2,600 & 5,614 & $5,503.55$ & - \\
\hline
\end{tabular}

From the data analysis, it follows that $97 \%$ of arable land is suitable for sowing crops after carrying out measures to improve the soil. Pastures and hayfields, in turn, require plastering and liming of the soil.

The landscape-ecological mapping of the territory has been carried out (Fig.1). 


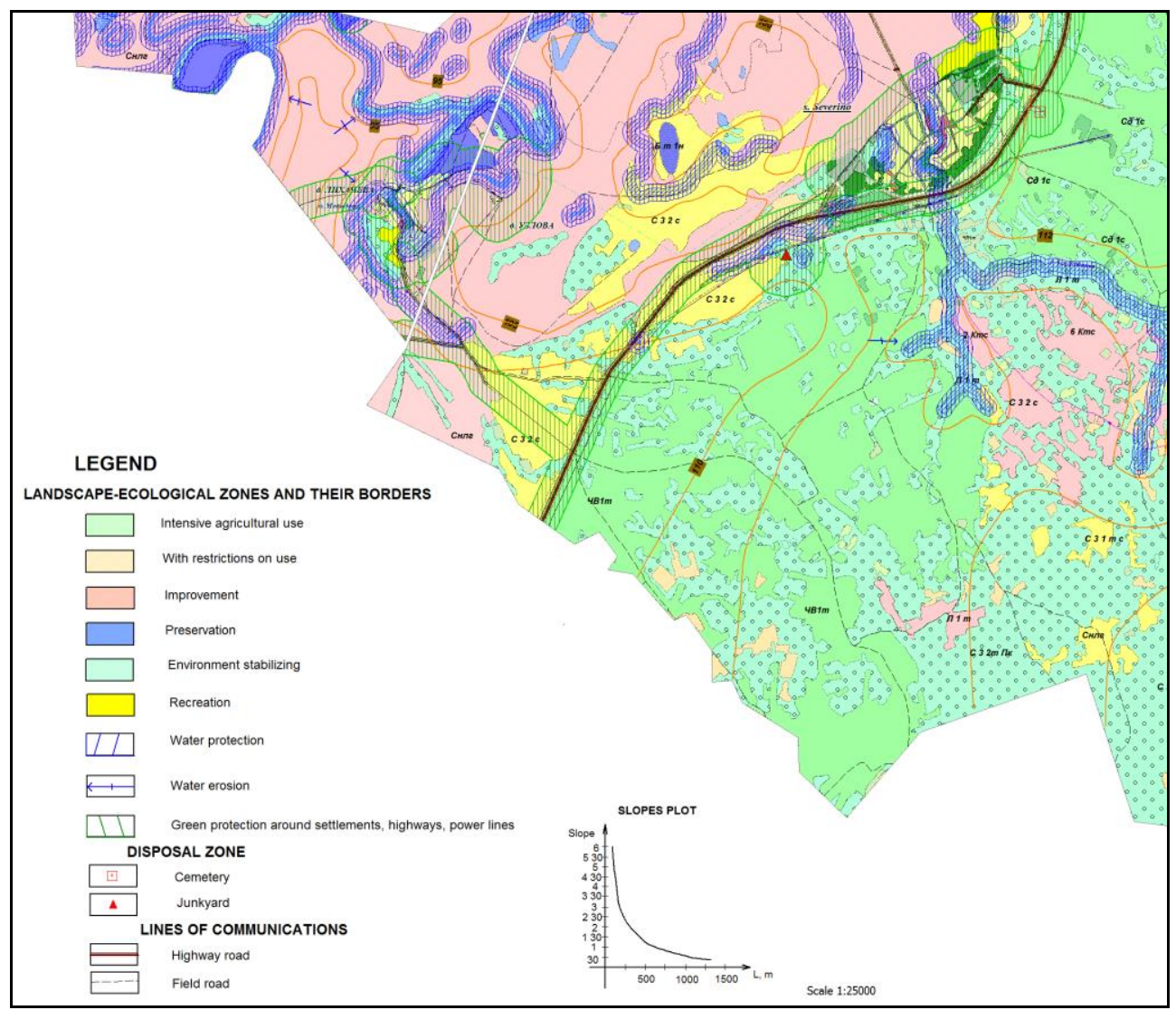

Fig. 1. The scheme of landscape-ecological zoning (authoring).

As a result of landscape-ecological mapping :

1. It has been established that negative natural, man-made and man-caused processes in the territory of the studied land use are manifested to a weak degree $-29 \%$, to an average degree $-33 \%$, and to a strong degree $-38 \%$.

2. The following zones were identified:

- Zone of intensive agricultural use (the area of the zone is 6,106.41 ha, this zone implies any permitted use)

- Zone with restrictions on land use (area of 5,585 ha, including areas: mediumeroded, medium washed, medium saline)

- Recovery zone (5,093 ha) with an improvement subzone. The recovery zone involves special measures (phytomeliorative, chemical, recultivation)

- Conservation zone (in the northern and north-western areas of agricultural land use, an area of 1,634 ha)

- Sanitary protection zones along transport arteries (sources of technogenic pollution), around disposal sites, see Figure 1 [4, 9, 8].

The formed landscape-ecological zones on the territory of the studied economy ensured the optimization of natural-economic systems, reinforcement of the elements of the ecological and economic framework and their rational organization of use, eliminating the manifestation of environmental risks $[1,8,5]$. 


\section{Conclusions}

In order to rationally organize the use of agricultural land, the analysis of the current organization and the ecological and economic status was made. It has been established that:

1. The arable lands of the studied farm are used for monoculture (wheat).

2. The current field road network system, which determined the boundaries of crop rotation fields, indicates that fields are not equal in area, and the inclusion of heterogeneous soils in fields $(54 \%)$ confirms that they are not equal in gross output $(68 \%)$.

3 . The direction of processing does not meet the requirements.

4. With the manifestation of wind and water erosion, the fields of crop rotations are only $27 \%$ protected from harmful winds.

5. Pasture lands are subject to moderate and strong salinization.

6. Hayfields have a disseminated, small contour character and are prone to salinization, waterlogging, and water erosion.

7. The influence of anthropogenic and technogenic processes is not taken into account in land use.

8. The authors of the article developed:

- A set of electronic thematic maps using the MapInfo Professional software product: anthropogenic and agrolandscapes maps, soil map and landscape-ecological zoning map, map of organization of the use of arable and forage lands, the purpose of which allowed us to study the morphological structure of landscapes, the state and quality of soils (Fig. 2).

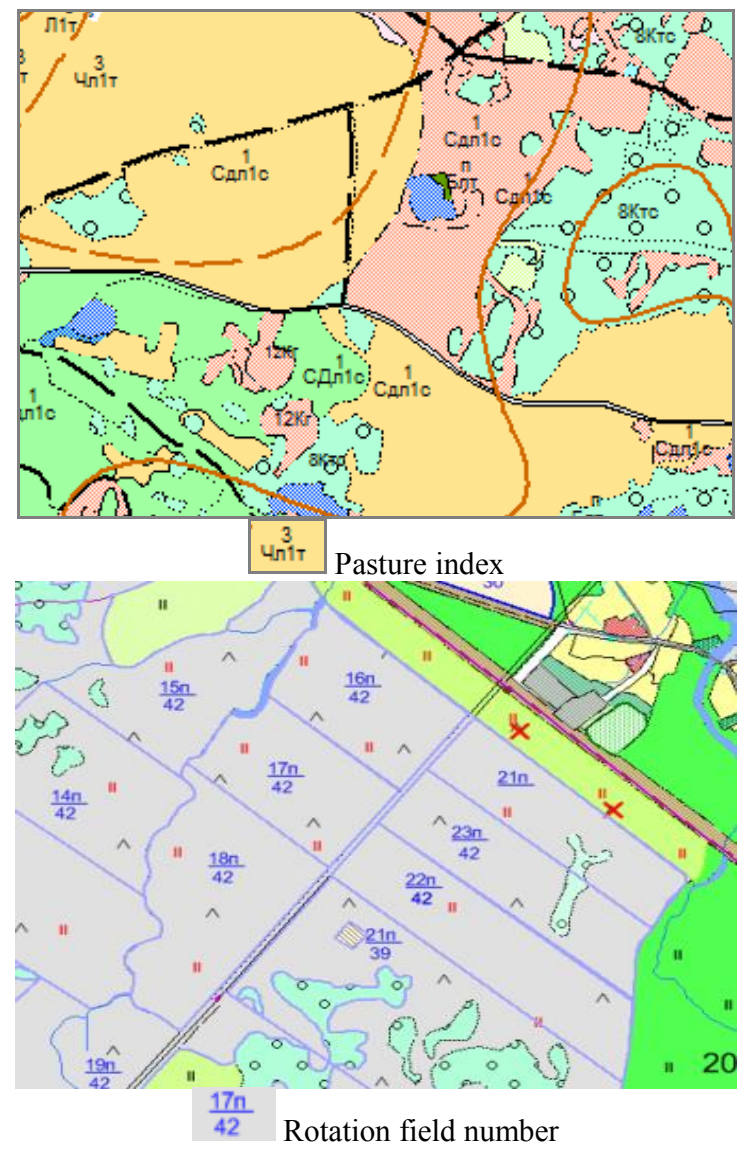

Fig. 2. Fragments of digital thematic maps (authoring): a) soil map; b) project. 
- The volumes of improvement, transformation and conservation of land, the value of which is equal to 223.43 thousand rubles, were determined. The economic efficiency of these measures will be $3.39 \%$ per year.

- A project for the rational organization of land use on a landscape-ecological basis, which included the optimization of natural-economic systems of agricultural land, was developed (Fig. 3).

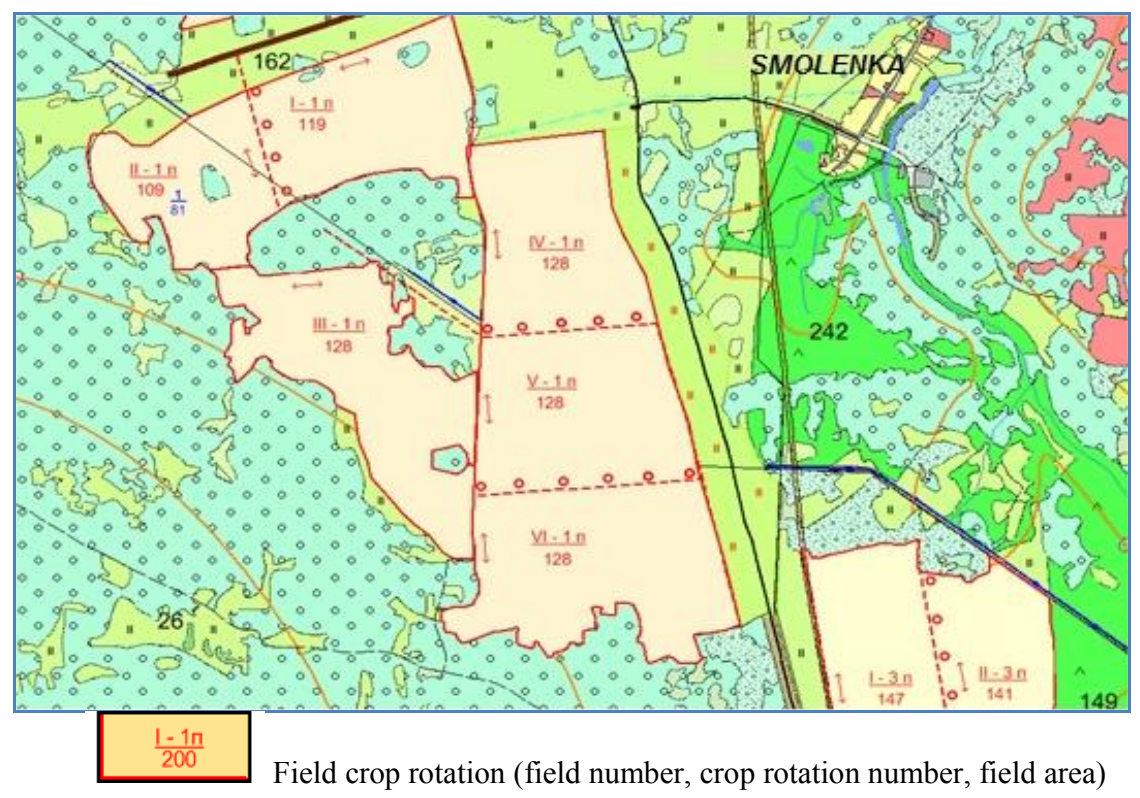

Fig. 3. Fragment of the project of rational organization of land use on a landscape-ecological basis (authoring).

The project proposes the developed system of crop rotations taking into account the established degree of environmental stress of arable land: field crop rotations have been preserved, out of crop land has been transferred to crop; soil-protective crop rotations were introduced with a ratio of grain crops and grasses (50\%:50\%). The system of fields, field roads, and four-row protective forest stands (12 $\mathrm{m}$ wide) has been improved. The volumes of improvement, transformation, and conservation of lands were determined. The economic efficiency of the project is determined by the growth of net income. The coefficients of the capital investments effectiveness for a number of activities vary from 0.37 to 0.49 . The payback period does not exceed the standard set.

In modern conditions, it remains relevant to develop a modern concept of legal, land management and landscape-ecological support of formation and sustainable development of agricultural land use. For this purpose, it is required:

1. Land monitoring. Soil monitoring is of particular importance. With a costly nature, it is he who will fully ensure the rational organization, use and protection of land (targeted use of land, optimization of natural-economic systems, the formation and development of a landscape-ecological framework, continued at the level of the administrative region) [11, $12,1,4]$.

2. To analyze the methodological foundations of land management (land management planning, land use management), based on the key provisions of the Russian concept of the formation of territories of sustainable development. 
3. To develop a draft land management scheme for agricultural land, as the basis for organizing the use of agricultural land, excluding the possibility of depersonalization in the use of agricultural land.

4. Preserve the agrarian campus system that has developed in the Tyumen region, ensuring its sustainable development in the field of agriculture and the economy as a whole [7].

\section{References}

1. M.A. Podkovyrova, A.M. Oleinik, A.A. Matveeva, International Journal of Civil Engineering and Technology, 9, 513-521 (2018)

2. D. Veteikis, P. Kavaliauskas, R. Skorupskas, et al., Landscape and Landscape Ecology, 348-358 (2015)

3. T. Durrant, R. Hiedever, Environmental monitoring, 11, 774-781 (2009) doi: $10.1039 / \mathrm{b} 818274 \mathrm{~b}$

4. T. Lacarce, C. Le Ba, J. Caesin, et al., Soil use and management, 25, 57-65 (2009) doi: 10.1111/j.1475-2743.2009.00194.UKC

5. C. Gardi, C. Bosco, E. Rusc, L. Montanarella, Environmental quality management, 21(5), 680-694 (2010) doi: org/10.1108/14777831011067953

6. V. Belton, T.J. Stewart, 374 (2003)

7. O. Binder, A.M. Oleynik, A.M. Podkovyrova, A.S. Piterskikh, I.O. Golubev, TEST E. M., 1876-1882 (2019)

8. M. He, Yu. Wang, Yo. Tong, Ya. Zhao, Ch. He, Land Use Policy, 94, (2020)

9. M.A. Podkovyrova, N.S. Ivanova, Agr. Econ. Russia, 80-86 (2019) doi: 10.32651/1911-80

10. L. N. Gilyova, M. A. Podkovyrova, Scientific statements of Belgorod State University, 2, 198-209 (2019)

11. L. T. Krupskaya, A. V. Leonenko, V. P. Zvereva, Contemporary Problems of Ecology, 6, 223-227 (2013)

12. E. N. Leisetskii, O. A. Marinina, T. N. Smekalova, Contemporary Problems of Ecology, 9(3), 366-375 (2016) doi: 10.1134/S1995425516030094

13. S. J. Pollard, UNESCO Encyclopedia of Life Support Systems, 285-289 (2008) 